\title{
SOFT COMPUTING APPROACH TO PREDICT INTRACRANIAL PRESSURE VALUES
}

\author{
Mario Versaci \\ Department of DICEAM, “Mediterranea” University, I-89122 Reggio Calabria, Italy
}

\begin{abstract}
Received 2014-01-30; Revised 2014-02-05; Accepted 2014-03-07
ABSTRACT

The estimation and the prediction of the values related to the Intracranial Pression (ICP) represents an important step for the evaluation of the compliance of the human brain, above all in those cases in which the increase of the ICP values determines high risk conditions for the patient. The regular therapy is neurosurgical but, waiting for it, it is needed an aimed pharmacological therapy leading to an overload of the kidneys' functionality. Thus, it becomes evident the necessity to set an effective and efficient procedure for the prediction of the ICP values with a suitable time recordings to mark the systematic pharmacological action addressed towards really necessary deliverings. The prediction techniques most commonly used in the literature, while providing a good window of time, are characterized by heavy computational complexity unappetizing to real time applications and technology transfer. In addition, ICP sampling techniques are not free from uncertainties due to affected elements (breath, heartbeat, voluntary/involuntary movement) requesting the manipulation of uncertain and imprecise data. Thus, the choice of predictive techniques of soft computing type appears reasonable firstly, because it manipulates data effectively with uncertainty and /or imprecision and, secondly, for the same time frame predictive requires are duce computational load. In this study the author presents a study of the prediction of the ICP values through a two factors fuzzy time series comparing the results with more sophisticated techniques.
\end{abstract}

Keywords: Intracranial Pressure, Prediction Systems, Soft Computing, Two Factors Fuzzy Time Series

\section{INTRODUCTION}

The intracranical ipertension (ICP) occurs thanks to the pressure of the endocranial content from out and in the same skull. The main reason why the ICP values increase lies in the fact that some brain lesionscause complications that often lead to the death of the patient. According to the theory of Monroe and Kellie, the skull can be considered as a rigid box which serves as a protection against external mechanical stresses. Inside, ICP values are governed by a special balance of volumes of liquor, brain parenchyma and blood volume. The skull, while in childhood can still enlarge itself thanks to the resilience of its walls, becomes rigid and inextensible in the adults. The encephalon subdue to pressure presents a modest adaptation over which it is irrepressible. Each increase in volume of the endocranial content will cause hypertension both for occupying space and disturbances in the blood/liquor circulation and the surrounding oedema, sometimes intense and wide. The therapy, when possible, is neurosurgical. Waiting for this, or when it can't be applied, an anti-oedema and hypotensive effectis obtained by daily drips. However, the parmacological therapy is not possible to be delivered systematically because of obvious reasons of eccessive overload by the kidney apparatus for which it is needed to dispose of a predictive procedure with an indicative sufficient timeline of the urgency of the pharacological delivering. Intracranial Pressure Monitoring (IPM) (Cai et al., 2013) provides ICP data and cerebral perfusion pressure with reactions of the brain to interventions and stimula. The monitoring devices are classified by the anatomy location and the type of system and can be intraventricular,subarachnoid, epidural and at optical fibres (Meng et al., 2013). These last ones, determine the changes of the quantity of the light reflected by a diaphragm, which detects the pressure and is placed in the spike of the optical fibre, gathering the ICP in the subdoral and intraventricular areas. It does not require to 
be replaced for the movement of the patient's head. The catheter, however, is fragile with problems of recalibration due to the positioning for which they are manipulated signals affected by uncertainty and/or inaccuracy for which the techniques of statistical prediction could not guarantee efficacy and efficiency above all in cases in which the average scientific literature holds doubts (Güiza et al., 2013; Qvarlander et al., 2013; Calcagno et al., 2014; Ismail and Mahpol, 2009; Sethukkarasi and Kannan, 2012). In addition, the excessive computational load of the usual statistical predictiontechniques hardly find acceptance within the technology transfer for the production of devices hospital monitoring.In recent years, the soft computing prediction techniques have been worked out with excellent results both in theoretical and applicative fields. In particular, remarkable results have been obtained by fuzzy and neuro-fuzzy techniques (Rahoma et al., 2011) by means of the construction of banks of naive fuzzy rules or with more sophisticated techniques of extraction of inferences directly from numerical data with the undoubted advantage of creating linguistic structures easily modifiable and/or updateable by the knowledge of the expert. However, since ICP depends on several patho-physiological factors, the structuring of the banks of fuzzy rules may be often complicated with obvious problem of explosion of the number of the rules for which it is necessary to drastically reduce the number of inputs. In addition, to underline the dynamic character of the prediction, the approach should be set on variations in subsequent samplings supported by specific statistical precursors indicative of a significant change of ICP. In this context, the prediction techniques based on fuzzy time series found wide acceptance in the scientific community in various fields of application, but so far, ICP prediction with fiber optic catheter did not produce significant results. (Versaci and Morabito, 2003; Suhartono and Lee, 2011; Elaal et al., 2010; Mammone et al., 2009; La Foresta et al., 2005; Josip and Wang, 2007; Morabito and Versaci, 2001; Lee et al., 2012). The purpose of this study regards the ICP prediction detected by an optical fibre catheter usingtwo factors fuzzy time series where the main factor is the ICP value at the end of a given time recording (minimum time necessary to the medicine delivered to start to act) while the second factor is represented by a particular statistical of the previous time recording parameter. The study is organized as follows. The following section is dedicated to the description of the database with a statistical- spectrum analysis. After, a brief description of the two factors fuzzy time series with the application of the prediction of the ICP values, sampled through an optical fibre catheter. Finally, the evaluation of the results and some conclusions to give hints for the discussion about future developments.

\section{THE EXPERIMENTAL DATABASE}

Data have been provided by "Bianchi Melacrino Morelli" Hospital of Reggio Calabria (Italy) and have been acquired for time spaces of two consecutive hours with optical fibre catheter. In particular, the database has been divided into training (40 and 30 signals of female and male subjects respectively) and testing (25 and 15 signals of male and female subjects respectively). In order to look for precursors of the ICP increase, for each patient it has been carried out a statistical analysis for time intervals of an hour, half an hour, 15 and $5 \mathrm{~min}$, detecting the values of minimum, maximum, mean, skewness variance and kurtosis. In Table 1 it is reported the analysis for intervals of half an hour related to a signal of male subject. The ICP negative values that appear have no medical/clinical meaning, but they are due to the measurements of the instrument in the experimental trials. From the analysis of the table, they come out signals of alert in which the maximum ICP value goes over the border of $15 \mathrm{~mm} \mathrm{Hg}$ (superior extreme of the whole of the numerical values thought as normal) and some situations at risk with the ICP values close to the above mentioned border. From the coefficients of correlation and covariance (Table 2) it can be observed the exiguity of negative values indicating that growing the first variables, the other one tends to decrease marking a pharmacological intervention which lowers the ICP level in the following time. The other values of the coefficient of correlation are very low (no linear ratio of mutual variation) but positive, indicating that growing a variable, it grows the other one, too. What just observed, is the same for the covariance, because linked to the coefficient of correlation. The ICP signal is weak, contamined by the noise due to the breathing and heart signals. The first signal, in subjects not affected by pathological conditions, has an average frequency of $1 \mathrm{~Hz}$ which becomes $2.17 \mathrm{~Hz}$ in a child; $1.17 / 1.33 \mathrm{~Hz}$ in the male adults and $1.33 / 1.5 \mathrm{~Hz}$ in the female adults. Observing the spectrum of the signal of intracranial pressure it is pointed out the breathing signal at $0.27 \mathrm{~Hz}$ while the component at a $1.7 \mathrm{~Hz}$ can be identified as heart signal. The filters designed are stop band filters- Butterworth type with polynomial approximators (soft transition between passing band and obscure band with no ondulations). 
Table 1. Statistical parameters on signal of IPM (male subjects)

\begin{tabular}{|c|c|c|c|c|c|c|}
\hline & $\begin{array}{l}\text { Max } \\
\text { not-filtered } \\
\text { /filtered }\end{array}$ & $\begin{array}{l}\text { Min } \\
\text { not-filtered } \\
\text { /filtered }\end{array}$ & $\begin{array}{l}\text { Mean } \\
\text { not-filtered } \\
\text { /filtered }\end{array}$ & $\begin{array}{l}\text { Variance } \\
\text { not-filtered } \\
\text { /filtered }\end{array}$ & $\begin{array}{l}\text { Skewness } \\
\text { not-filtered } \\
\text { /filtered }\end{array}$ & $\begin{array}{l}\text { Kurtosis } \\
\text { not-filtered } \\
\text { /filtered }\end{array}$ \\
\hline I half an hour & $7.986 / 4.987$ & $-0.398 /-1.2 .36$ & $2.5642 / 2.3987$ & $0.7925 / 0.3198$ & $0.4412 / 0.0687$ & $3.6874 / 3.210$ \\
\hline II half an hour & $6.9250 / 4.169$ & $-0.874 / 0.4252$ & $2.4985 / 2.3691$ & $0.7841 / 0.4128$ & $0.5142 / 0.3320$ & $3.3322 / 2.9145$ \\
\hline II I half an hour & $7.986 / 5.0874$ & $-0.598 / 0.0725$ & $2.1983 / 2.0321$ & $0.4987 / 0.3014$ & $0.6021 / 0.2824$ & $4.5931 / 3.7400$ \\
\hline IV half an hour & $14.056 / 9.065$ & $0.1245 / 0.6398$ & $2.4527 / 2.0354$ & $0.9413 / 0.5050$ & $0.6983 / 0.3652$ & $4.7411 / 4.2138$ \\
\hline V half an hour & $14.897 / 13.598$ & $-0.130 /-0.698$ & $2.7425 / 2.145$ & $0.8972 / 0.4477$ & $0.3752 / 0.3212$ & $3.4762 / 3.0204$ \\
\hline VI half an hour & $15.276 / 13.991$ & $-3.587 /-2.326$ & $2.2125 / 1.7581$ & $5.3698 / 4.888$ & $0.8123 / 0.7523$ & $3.7883 / 3.0402$ \\
\hline VII half an hour & $9.658 / 6.035$ & $-1.910 /-1.129$ & $0.7803 / 0.7425$ & $0.6051 / 0.3122$ & $0.2682 / 0.1963$ & $2.9804 / 2.5630$ \\
\hline VIII half an hour & $16.052 / 13.965$ & $-3.154 /-2.698$ & $0.0377 / 0.0336$ & $0.6121 / 0.3483$ & $0.3411 / 0.2140$ & $3.7892 / 2.9835$ \\
\hline
\end{tabular}

Table 2. Correlation and covariance on not filtered signal of IPM (male subjects)

\begin{tabular}{|c|c|c|c|c|c|c|c|c|c|}
\hline \multirow[b]{2}{*}{ I half an hour- } & \multicolumn{2}{|c|}{ Correlation } & \multicolumn{3}{|c|}{ Covariance } & \multicolumn{2}{|c|}{ Correlation } & \multicolumn{2}{|c|}{ Covariance } \\
\hline & 1.0000 & -0.0356 & 0.8136 & -0.01550 & V half an hour & 1.0000 & 0.0570 & 0.9542 & 0.1266 \\
\hline II half an hour & -0.0356 & 1.0000 & -0.0155 & 0.72450 & VI half an hour & 0.0573 & 1.0000 & 0.1266 & 5.3650 \\
\hline II half an hour- & 1.0000 & 0.0037 & 0.6782 & 0.01440 & VI half an hour & 1.0000 & 0.0733 & 6.2620 & 0.1305 \\
\hline III half an hour & 0.0037 & 1.0000 & 0.0144 & 0.44120 & VII half an hour & 0.0733 & 1.0000 & 0.1305 & 0.5885 \\
\hline III half an hour- & 1.0000 & 0.0124 & 0.4742 & 0.00830 & VII half an hour & 1.0000 & 0.1500 & 0.5885 & 0.0840 \\
\hline IV half an hour & 0.0124 & 1.0000 & 0.0104 & 0.98630 & VIII half an hour & 0.1506 & 1.0000 & 0.0842 & 0.6110 \\
\hline IV half an hour- & 1.0000 & 0.0024 & 1.0000 & 0.01520 & & & & & \\
\hline V half an hour & 0.0024 & 1.0000 & 0.0152 & 1.00000 & & & & & \\
\hline
\end{tabular}

The first, centered at a $0.27 \mathrm{~Hz}$, removes the breathing signal with a band wideness between 0.008 and 0.048 $\mathrm{Hz}$. The second one, centered at a 1.7 , removes the heart signal with a band wideness between 0.05 and $0.22 \mathrm{~Hz}$. To eliminate the spurious peaks due to movements of the body, they have been used some high-pass filters. Table 1 reports the statistical parameters of the filtered signal (subdued than the not filtered one) observing that the mean varies a little in the first three halves an hour and increases in the last time interval respect the previous higher value, almost foreseeing the irregular trend of the following $2 \mathrm{~h}$. The variance too assumes higher values in the last half an hour, while the skewness highlights a good symmetry in the distribution.

\section{A BRIEF OVERVIEW ON TWO FACTORS FUZZY TIMESERIES}

Because the prediction of the ICP values suggests the clinician the timing of the pharmacological intervention, it appears clear it should have at disposal a suitable predictive instrument able to foresee with reliability the ICP levels with a time recording equal almost to the drug's start-up. Because IPM is carried out above all on terminally ill patients whose pharmacological delivering occurs exclusively intravenously, it appears sufficient a time recording $\mathrm{w}$ of $15 \mathrm{~min}$. In this study, the author has put his attention in the prediction systems based on two factors fuzzy time series (Versaci and Morabito, 2003) where the secondary factor is represented by the sampling mean on 15 min of the ICP values, while the main factories represented by the ICP values at the end of the following fifteen.

\subsection{Definition of Fuzzy Time Series}

Whatever it is the numerical time series, it represents a one-dimensional dynamic process and the time observations are represented by crisp values. Side by side, in each fuzzy time series the observations are represented by linguistic variables of fuzzy type. If we point with $\mathrm{X}$ the Universe of the Discourse with $\mathrm{n}$ its cardinality (number of its elements), with $\mathrm{H}(\mathrm{t})(\mathrm{t}=0,1,2, \ldots)$ a group of real numbers and with $B(t)$ a collection of $f_{i}(t)$ (set of membership functions defined on $\mathrm{X}$ to values in $[0$, 1]), B(t) represents a fuzzy time series of $H(t)$.

\subsection{Relation of Causality}

If at time $t, B(t)$ is caused by $B(t-1)$, the relation between them can be expressed in terms of $M(t, t-1$, fuzzy relation as follows:

$$
\mathrm{B}(\mathrm{t})=\mathrm{B}(\mathrm{t}-1)^{\circ} \mathrm{M}(\mathrm{t}, \mathrm{t}-1)
$$

If we referred $\mathrm{B}(\mathrm{t})$ to a main factor, a new fuzzy time series, $\mathrm{C}(\mathrm{t})$, would be referred to the secondary factor so to both the time series give meaningful indications about the predictability of the parameter under examination. 


\subsection{The Core of the Approach: The Steps of the Algorithm}

Step 1: Universe of the discourse of the main factor

The first step of the algorithm concerns the definition of the universe of discourse of the main factor, which is defined as follows:

$$
\mathrm{X}=[\mathrm{md}-\delta, \mathrm{ni}+\delta] \text { With }\left\{\begin{array}{c}
\delta \text { positive rael } \\
\text { md max imum decrease } \\
\text { mi max imumincrease }
\end{array}\right.
$$

To guarantee the compactness, it appears useful to consider $\mathrm{X}$ as a topological covering of $\mathrm{n}$ sub domains $\mathrm{X}=\mathrm{x}_{1} \mathrm{U}_{\mathrm{x} 2} \mathrm{U} \ldots \mathrm{U}$ so to admit a finished sub-covering. Moreover, each $\mathrm{x}_{\mathrm{j}}$ sub-domain is identified by a $\mathrm{L}_{\mathrm{i}}$ linguistic variable, $\mathrm{s}$ :

$$
f_{L_{i}}\left(x_{i}\right)\left\{\begin{array}{l}
i=1, \ldots, h \\
j=1, \ldots, n
\end{array}\right.
$$

Step 2: Universe of the discourse of the secondary factor It can be defined as:

$$
\mathrm{Y}[\min \text { (secondary factor) } \max (\text { secondary factor) }]
$$

Once represented its minimum and maximum values. However, it is important to emphasize that $X$ is structured on the variation of its values while $\mathrm{Y}$ is structured on its values. As for the first factor and for reasons of compactness, $\mathrm{Y}$ too has to have both the topological structures of recovering admitting the finished sub-recovering and the labelling through the fuzzy sets as follows:

$$
f_{L_{i}}\left(x_{i}\right)\left\{\begin{array}{l}
i=1, \ldots, h \\
j=1, \ldots, n
\end{array}\right.
$$

Finally, it is important to observe that the value of $\mathrm{f}_{\mathrm{L}_{\mathrm{i}}}\left(\mathrm{x}_{\mathrm{j}}\right)$ e $\mathrm{f}_{\mathrm{B}_{\mathrm{i}}}\left(\mathrm{y}_{\mathrm{j}}\right)$ are value taken from the visual inspection of the signals of the main and secondary factors.

Step 3: Data fuzzification and choice of the predicting time recording

The process of fuzzification is based on the variation of the main factor which if belonging to the interval it is known its maximum value, so this last one becomes the fuzzification of $\gamma$. Similarly as for the secondary factor.
If we point with the time record of prediction and with $b(t-1)$ the fuzzified variation of the main factor between $\mathrm{t}-1$ and $\mathrm{t}-2$, the criterion vector $\mathrm{CV}(\mathrm{t})$ and the operational matrix $\mathrm{O}^{\alpha}(\mathrm{t})$ (at time $t$ ) they assume the form:

$$
\begin{aligned}
& \mathrm{CV}(\mathrm{t})=\mathrm{a}(\mathrm{t}-1)=\left[\mathrm{CV}_{1} \mathrm{CV}_{2} \ldots \mathrm{CV}_{\mathrm{n}}\right] \\
& \mathrm{O}^{\mathrm{a}}=\left[\begin{array}{c}
\mathrm{a}(\mathrm{t}-2) \\
\mathrm{a}(\mathrm{t}-3) \\
\ldots \\
\mathrm{a}(\mathrm{t}-\mathrm{a})
\end{array}\right]=\left[\begin{array}{cccc}
\mathrm{O}_{11} & \mathrm{O}_{12} & \ldots & \mathrm{O}_{1 \mathrm{n}} \\
\mathrm{O}_{21} & \mathrm{O}_{22} & \ldots & \mathrm{O}_{2 \mathrm{n}} \\
\ldots & \ldots & \ldots & \ldots \\
\mathrm{O}_{(\mathrm{a}-1) 1} & \mathrm{O}_{(\mathrm{a}-1) 2} & \ldots & \mathrm{O}_{(\mathrm{a}-1) \mathrm{n}}
\end{array}\right]
\end{aligned}
$$

With the specifications:

$$
\begin{aligned}
& 0 \leq \mathrm{C}_{\mathrm{i}} \leq 1 \quad 1 \leq \mathrm{j} \leq \mathrm{n} \\
& 0 \leq 0_{\mathrm{ij}} \leq 1 ; 1 \leq \mathrm{j} \leq \alpha-1 ; \quad 1 \leq \mathrm{j} \leq \mathrm{n}
\end{aligned}
$$

Similarly, it is necessary to treat the secondary factor so, pointing it with $\mathrm{T}(\mathrm{t})$, its fuzzified series $\mathrm{c}(\mathrm{t})$ gets the form of $T(t)=c(t-1)=\left[T_{1} T_{2} \ldots T_{n}\right]$.

Step 4: Link between two time series

Following Chen's model, the link among the time series occurs through the $\mathrm{C}(\mathrm{t})$ vector, the $\mathrm{O}^{\mathrm{a}}(\mathrm{t})$ and $\mathrm{S}(\mathrm{t})$ matrix as follows:

$$
\begin{aligned}
& \mathrm{M}(\mathrm{t})=\mathrm{O}^{\omega}(\mathrm{t}) \otimes \mathrm{T}(\mathrm{t}) \otimes \mathrm{CV}(\mathrm{t})= \\
& {\left[\begin{array}{cccc}
\mathrm{O}_{11} \times \mathrm{T}_{1} \mathrm{CV}_{1} & \mathrm{O}_{12} \times \mathrm{T}_{2} \mathrm{CV}_{2} & \ldots & \mathrm{O}_{1 \mathrm{n}} \times \mathrm{T}_{\mathrm{n}} \mathrm{CV}_{\mathrm{n}} \\
\mathrm{O}_{21} \times \mathrm{T}_{1} \mathrm{CV}_{1} & \mathrm{O}_{22} \times \mathrm{T}_{2} \mathrm{CV}_{2} & \ldots & \mathrm{O}_{1 \mathrm{n}} \times \mathrm{T}_{\mathrm{n}} \mathrm{CV}_{\mathrm{n}} \\
\ldots & \ldots & \ldots & \ldots \\
\mathrm{O}_{(\mathrm{a}-1) 1} \times \mathrm{T}_{1} \mathrm{CV}_{1} & \mathrm{O}_{(\mathrm{a}-1) 2} \times \mathrm{T}_{2} \mathrm{CV}_{2} & \ldots & \mathrm{O}_{(\mathrm{a}-1) \mathrm{n}} \times \mathrm{T}_{\mathrm{n}} \mathrm{CV}_{\mathrm{n}}
\end{array}\right]} \\
& \quad\left[\begin{array}{cccc}
\mathrm{M}_{11} & \mathrm{M}_{12} & \ldots & \mathrm{M}_{1 \mathrm{n}} \\
\mathrm{M}_{21} & \mathrm{M}_{22} & \ldots & \mathrm{M}_{2 \mathrm{n}} \\
\ldots & \ldots & \ldots & \ldots \\
\mathrm{M}_{(\mathrm{a}-1) 1} & \mathrm{M}_{(\mathrm{a}-1) 2} & \ldots & \mathrm{M}_{(\mathrm{a}-1) \mathrm{n}}
\end{array}\right]
\end{aligned}
$$

Following, the fuzzified variation of $\mathrm{B}(\mathrm{t})$ (indicated with $b(t))$ gets the following form:

$$
b(t)=\left[\begin{array}{c}
\max \left(M_{11}, M_{21}, \ldots, M_{(a-1) 1}\right) \\
\max \left(M_{12}, M_{22}, \ldots, M_{(a-1) 2}\right. \\
\max \left(\mathrm{RM}_{1 \mathrm{n}}, M_{2 n}, \ldots, M_{(a-1) n}\right.
\end{array}\right]
$$

Step 5: Main factor defuzzification

Conceptually, the present procedure is almost simple because it is based on the following supposition in terms of fuzzy rule: 
IF membership value (predicted variation) $=0$ THEN predicted variation $=0$ ELSE

IF maximum membership value (fuzzified predicted variation $)==$ THEN predicted variation $==$ midpoint $\left(\mathrm{x}_{\mathrm{j}}\right)$

However, the scientific literature presents a variety of modifications of such algorithm. The most important one differentiates itself exclusively in the step of defuzzification. Specifically, using the concept of level of-significance $(b(t))_{\sigma}$ of the fuzzified predicted variation $\mathrm{b}(\mathrm{t})$, the fuzzification gets the more elaborated form:

$$
b(t)=\left[b_{1} b_{2} \ldots b_{n} ;(a(t)) \sigma=\left[b_{1 \sigma} b_{2 \sigma} \ldots b_{n \sigma}\right.\right.
$$

With the thesis: 0 Moreover:

IF $\mathrm{f}_{\mathrm{i}} \geq \sigma$ THEN $\mathrm{f}_{\mathrm{i} \sigma}=\mathrm{f}_{\mathrm{i}}$ ELSE IF $\mathrm{f}_{\mathrm{i}}<\sigma$ THEN $\mathrm{f}_{\mathrm{i}}=$ IF $(\mathrm{b}(\mathrm{t}))_{\sigma}==0$ then prediction variation $==0$

ELSE IF membership value of $(b(t))_{\sigma}$ has only one maximum in $\mathrm{x}_{\mathrm{j}}$ then predicted variation is its midpoint

\section{NUMERICAL RESULTS}

By means of MatLab® Toolbox the proposed procedures based on two factors fuzzy time series and its modification (with $\alpha=0.5$ for reasons of fuzzy overlapping) for ICP prediction have been implemented through a time recording of $15 \mathrm{~min}$ and applied to the database of filtered training. Then, the ICP values have been taken from the database of filtered testing and compared with the values obtained through a system of fuzzy inference with automatic extraction generated by genfis procedure and tuned by an fis approach with two inputs (input \#1: ICP value at the end of the $15 \mathrm{~min}$ before the prediction; input \#2: ICP mean value in the $15 \mathrm{~min}$ before the prediction) and an output (ICP value at the end of the 15 min of prediction) structured with a bank of fuzzy rules made up of 5 rules at multiple antecedent (good compromise between number of rules and computational complexity, useful for real time applications). The results, in terms of RMSE ( $\mathrm{mmHg}$ ) and CPU-time are reported in Table 3 .

Table 3. Comparison in terms of RMSE ( $\mathrm{mmHg}$ ) of the results obtained through the proposed procedure and systems of inference of Sugeno fuzzy type (GENFIS and ANFIS Approach).

\begin{tabular}{|c|c|c|c|c|c|c|c|}
\hline $\begin{array}{l}\text { Male } \\
\text { subjects }\end{array}$ & $\begin{array}{l}\text { RMSE } \\
(\mathrm{mmHg}) \\
\text { GENFIS } \\
\text { and ANFIS }\end{array}$ & $\begin{array}{l}\text { RMSE } \\
(\mathrm{mmHg}) \\
\text { fuzzy time } \\
\text { series }\end{array}$ & $\begin{array}{l}\text { RMSE } \\
(\mathrm{mmHg}) \\
\text { modified } \\
\text { fuzzy time } \\
\text { series }(\sigma=0.5)\end{array}$ & $\begin{array}{l}\text { Female } \\
\text { subjects }\end{array}$ & $\begin{array}{l}\text { RMSE } \\
(\mathrm{mmHg}) \\
\text { GENFIS } \\
\text { and ANFIS }\end{array}$ & $\begin{array}{l}\text { RMSE } \\
(\mathrm{mmHg}) \\
\text { fuzzy time } \\
\text { series }\end{array}$ & $\begin{array}{l}\text { RMSE } \\
(\mathrm{mmHg}) \\
\text { modified } \\
\text { fuzzy time } \\
\text { series }(\sigma=0.5)\end{array}$ \\
\hline \#1 & 1.05 & 1.03 & 1.06 & $\# 1$ & 1.04 & 1.07 & 1.05 \\
\hline$\# 2$ & 1.01 & 0.98 & 1.02 & $\# 2$ & 1.15 & 1.19 & 1.18 \\
\hline \#3 & 0.97 & 0.94 & 0.98 & \#3 & 1.13 & 1.11 & 1.10 \\
\hline \#4 & 0.94 & 0.99 & 0.97 & $\# 4$ & 0.98 & 1.01 & 1.03 \\
\hline$\# 5$ & 1.03 & 0.98 & 1.00 & $\# 5$ & 0.99 & 1.04 & 1.01 \\
\hline \#6 & 1.11 & 1.07 & 1.13 & \#6 & 0.99 & 1.04 & 1.00 \\
\hline \#7 & 1.09 & 1.05 & 1.08 & $\# 7$ & 1.01 & 1.02 & 0.99 \\
\hline \#8 & 1.18 & 1.14 & 1.16 & \#8 & 1.11 & 1.09 & 1.09 \\
\hline \#9 & 1.04 & 1.07 & 1.02 & $\# 9$ & 1.14 & 1.18 & 1.16 \\
\hline \#10 & 1.04 & 1.06 & 1.03 & $\# 10$ & 1.15 & 1.17 & 1.16 \\
\hline \#11 & 1.03 & 1.01 & 1.05 & \#11 & 1.15 & 1.12 & 1.14 \\
\hline \#12 & 0.94 & 1.00 & 0.97 & \#12 & 0.99 & 1.03 & 1.01 \\
\hline \#13 & 0.99 & 0.96 & 0.94 & \#13 & 1.12 & 1.14 & 1.11 \\
\hline \#14 & 0.98 & 0.94 & 0.93 & $\# 14$ & 1.07 & 1.09 & 1.06 \\
\hline \#15 & 0.96 & 0.94 & 0.95 & \#15 & 0.88 & 0.94 & 0.90 \\
\hline \#16 & 1.15 & 1.03 & 1.14 & & & & \\
\hline \#17 & 1.11 & 1.03 & 1.13 & & & & \\
\hline \#18 & 1.14 & 1.09 & 1.12 & & & & \\
\hline \#19 & 0.98 & 1.04 & 1.01 & & & & \\
\hline \#20 & 0.99 & 1.02 & 1.00 & & & & \\
\hline \#21 & 0.89 & 0.93 & 0.92 & & & & \\
\hline \#22 & 0.90 & 0.94 & 0.89 & & & & \\
\hline \#23 & 1.12 & 1.07 & 1.14 & & & & \\
\hline \#24 & 1.12 & 1.04 & 1.10 & & & & \\
\hline \#25 & 1.09 & 1.04 & 1.09 & & & & \\
\hline
\end{tabular}




\section{SOME DUTIFUL COMMENTS}

All simulations have shown good adhesion of RMSE and CPU-time values obtained by means of fuzzy inference techniques and two fuzzy time-series factors. In particular, the modified methodology produces a better adhesion even if there is a reduced increasing of computational load compared to the standard methodology (without $\alpha$ ). RMSE values content and appear to be oscillating around the unit of $\mathrm{mm} \mathrm{Hg}$ for which the maximum error that can be accomplished is entirely manageable from a simple instrumental monitoring of the patient without excessive pharmacological doses (in the sense that false positives and false negatives can be regarded as equivalent and with very little detrimental to the safety of the patient). Then, the use of two factors fuzzy time series are fully comparable to the techniques of extraction of fuzzy inference directly from numerical data with operation of tuning notoriously expensive in terms of computational load and therefore unappetizing in areas of technology transfer.

\section{CONCLUSION}

The present study has been entirely dedicated to the prediction of ICP values in patients affected by cerebral hypertension through the exploitation of two factors fuzzy time series in which the main factor is represented by the last ICP value sampled in a time record, while the secondary factor is represented by the ICP mean value at the previous time record. The elaborations have been carried out with statistical techniques allowing the detection of abnormal situations that need special medical attention and require appropriate inquiries to pharmacological interventions. Because ICP signal is weak and contaminated by respiratory and cardiac artifacts, it was necessary an adequate filtering with emphasis to the results that would otherwise be hardly visible. Finally, they not have been any carried out predictions with two factor fuzzy time series (of which a modified version). The obtained results can be considered encouraging both in terms of RMSE and CPU-time, of proposed approach based on two factors fuzzy time series can be wholly comparable with the most sophisticated techniques of fuzzy inference with automatic extraction and even more significant because obtained with relatively low computational costs. RMSE and CPU-time. In particular, the quality of the obtained results by the proposed approaches increases considering that RMSE calculated by fuzzy systems well-known in scientific literature is lowered as more refined is the partition of the membership functions and the most realistic is the choice of fuzzy rules that governing the system. But, fuzzy rules definition can be complex even if the problem under study can be considered well known. Finally, the covering of all possible cases over input-output space can be difficult or the explosion problem takes place with obvious contrasts of antagonism. The perspectives of research can concern the improvement of the systems proposed (time series at multiple factor), maybe with synergies of different concerned areas and the use of more sophisticated instruments of analysis and synthesis very interesting for real-time application and technology transfer.

\section{REFERENCES}

Cai, T., X. Tongand and G. Chen, 2013. Monitoring intracranial pressure based on F-P. Proceedings of the 4th Asia Pacific Optical Sensors Conference, (OSC' 13), China. DOI: 10.1117/12.2031586

Calcagno, Salvatore, L. Foresta, Fabio and Versaci, 2014. Independent component analysis and discrete wavelet transform for artifact removal in biomedical signal processing. Am. J. Applied Sci., 11: 57-68. DOI: 10.3844/ajassp.2014.57.68

Elaal, A., K. Ashraf, Hefny, A. Hesham and A. Elwahab et al., 2010. Constructing fuzzy time series model based on fuzzy clustering for a forecasting. J. Comput. $\quad$ Sci., 6: 735-739. DOI: $10.3844 /$ jcssp.2010.735.739

Güiza, F., B. Depreitere, I. Piper, G. Van Den Berghe, and G. Meyfroidt, 2013. Novel methods to predict increased intracranial pressure during intensive care and long-term neurologic outcome after traumatic brain injury: Development and validation in a multicenter. Crit. Care Med., 41: 554-564. DOI: 10.1097/CCM.0b013e3182742d0a, PMID: 23263587

Ismail, Z., A. Yahya and K.A. Mahpol, 2009. Forecasting peak load electricity demand using statistics and rule based approach. Am. J. Applied Sci., $\quad 6$ : $1618-1625 . \quad$ DOI: 10.3844/ajassp.2009.1618.1625

Josip, V.J. and W. Wang, 2007. Data-driven forecasting schemes: Evaluation and applications. J. Comput. Sci., 3: 747-753. DOI: 10.3844/jcssp.2007.747.753 
La Foresta, F., Morabito, F.C., Azzerboni, B., Ipsale, M, 2005. PCA and ICA for the extraction of EEG dominant components in cerebral death assessment. Proceedings of the International Joint Conference on Neural Networks, 4: 2532-2537. DOI: 10.1109/IJCNN.2005.1556301

Lee, M.H., Nor, Suhartono, M. Elena and Sadaei et al., 2012. Fuzzy time series: An application to tourism demand forecasting. Am. J. Applied Sci., 9: 132140. DOI: 10.3844/ajassp.2012.132.140

Mammone, N., G. Inuso, F.L. Foresta, M. Versaci and F.C. Morabito, 2009. Clustering of entropy topography in epileptic electroencephalography. Neural Comput. Applic., 20: 825-833. DOI: 10.1007/s00521-010-0505-2

Meng, X., K.D. Browne, S.M. Huang, C. Mietus and D.K. Cullen et al., 2013. Dynamic evaluation of a digital wireless intracranial pressure sensor for the assessment of traumatic brain injury in a swine model. IEEE Trans. Microwave Theory Techniques, 61: 316325. DOI: 10.1109/TMTT.2012.2224361

Morabito, F.C. and M. Versaci, 2001. A fuzzy neural approach to localizing holes in conducting plates. IEEE Trans. Magnet., 37: 3534-3537. DOI: $10.1109 / 20.952655$
Qvarlander, S., N. Sundström, J. Malm and A. Eklund, 2013. Postural effects on intracranial pressure: Modeling and clinical evaluation. J. Applied Physiol., 115: 1474-1480. DOI: 10.1152/japplphysiol.00711.2013

Rahoma, W.A., A.U. Rahoma and A.H. Hassan, 2011. Application of neuro-fuzzy techniques for solar radiation. J. Comput. Sci., 7: 1605-1611. DOI: 10.3844/jcssp.2011.1605.1611

Sethukkarasi, R and A. Kannan, 2012. A Dynamic temporal neuro-fuzzy inference system for mining medical databases. J. Comput. Sci., 8: 1924-1931. DOI: 10.3844 jcssp.2012.1924.1931

Suhartono and M.H. Lee, 2011. A hybrid approach based on winter's model and weighted fuzzy time series for forecasting trend and seasonal data. J. Math. Stat., 7: 177-183. DOI: 10.3844/jmssp.2011.177.183

Versaci, M. and F.C. Morabito, 2003. Fuzzy time series approach for disruption prediction in tokamak reactors. IEEE Trans. Magnet., 39: 1503 1506. DOI: 10.1109/TMAG.2003.810365 